ISSN 1516-635X Jul - Sept 2015 / v.17 / n.3 / 399-404

http://dx.doi.org/10.1590/1516-635x1703399-404

\section{New Occurance of Avian Encephalomyelitis in Broiler - Is this an Emerging Disease?}

Technical Note

\section{-Author(s)}

\section{Freitas ES de}

Back $A^{\prime}$

MercoLab Laboratórios Ltda

\section{-Mail Address}

Corresponding author e-mail address Freitas ES de

Rua Maringá, 2388, São Cristovão, CascavelPR, Caixa Postal 4040, CEP 85816-280

Phone: 55 (45) 99436300

Email: edmilsonfreitas@hotmail.com

\section{EKeywords}

Reemerging, disease, young chickens, virus.

\section{ABSTRACT}

Avian encephalomyelitis is caused by an Hepatovirus and primarily affects chickens. Chickens of all ages are susceptible to the virus, but the nervous symptoms are manifested only in young chicks, between one to five weeks of age. During the last thirty years, avian encephalomyelitis appeared to be well controlled by breeder vaccination. However, the increase of the number of cases is causing concern in the poultry industry. In the present study, we performed a retrospective analysis of the cases presenting histological lesions compatible with avian encephalomyelitis in broilers. The evaluated cases affected broilers from one to 35 days old from the southern region of Brazil. Only cases with compatible microscopic lesions and associated with clinical symptoms in the field were considered. In addition the histopathological diagnosis, sera were tested by ELISA (Enzyme-Linked Immunosorbent Assay). Considering the clinical, histopathological, and serological evidences, the disease was confirmed, showing an increase in outbreaks from the last quarter of 2012, extending through 2013. The cause of this increase is not clear, although we suspect vaccine or vaccination error. Enhancing vaccinated breeders flocks monitoring before the beginning of egg production and/or using a protocol with two vaccinations is recommended.

\section{INTRODUCTION}

Avian encephalomyelitis is an infectious disease of poultry caused by Hepatovirus, belonging to the genus Enterovirus. Chickens are primarily affected, but turkeys and other species of birds have also been reported as natural hosts (Calnek, 2008; Vilarreal, 2009). The transmission of the virus is both vertical and horizontal. Vertical transmission tends to cause higher losses because day-old chicks are affected. This happens when breeders with no immunity are infected during the egg production period and transmit the virus to progeny. The virus is horizontally transmitted by the ingestion of feed, litter, or contaminated water (Back, 2010; Calnek, 2008, Calnek, 1998). In this case, the disease is less severe and tends to affect older chickens.

Although poultry of all ages are susceptible, under natural conditions, symptoms are manifested only in chicks from one to three weeks of age. The clinical signs are predominantly neurological and are variable. Chicks show ataxia, incoordination, paralysis, and prostration (Back, 2010). Fast tremors, particularly in the head and neck, are the classic clinical sign of the disease (Martins \& Silva, 2009). Surviving birds may become blind due to corneal opacity. According to Taylor et al. (1955), breeder hens may present egg production drop; however, they do not develop neurological clinical signs.

According to Calnek (2008), the only gross lesions observed in outbreaks that affect young chickens are pale areas in the proventriculus 
and gizzard muscles, but no bigger than a pinhead. Presumptive diagnosis is based on clinical signs presented in chicks. However, the disease is only definitively confirmed by laboratory exams. Among the available techniques, histopathology is considered of essential, and provides the definitive diagnosis of the disease, as demonstrated by the pathognomonic lesions in various tissues, such as the central nervous system, pancreas, proventriculus, gizzard, and heart (Swayne, 2008; Randall, 1991). The microscopic lesions in the central nervous system are found in the brain (cerebral peduncle, cerebellum, brain stem) and in the spinal cord and consist of degeneration and necrosis of neurons, perivascular lymphocytic cuffing, and gliosis with formation of glial nodules. In the cerebellum, there are areas of necrosis or loss of Purkinje cells and replacement by glial nodules that extend into the molecular layer of the gray matter. Neuronal lesions of central chromatolysis, shrinkage and increased basophilia, satellitosis, and neuronophagia are typically found in neuron clusters (nuclei) in the brain stem, arbor vitae of the cerebellum, and lateral horn (gray matter) of the spinal cord. Central chromatolysis of neurons is characterized by rounding of the cell contour and displacement of the Nissl granules to the cell periphery. Dorsal root ganglia may present multifocal nodular collections of lymphocytes (Martins \& Silva, 2009; Roy et al, 2009; Villareal, 2009; Calnek, 2008; Swayne, 2008; Taylor et al, 1995; Randall, 1991). Furthermore, serological tests may also contribute for the diagnosis of the disease, as well as virus isolation (Calnek, 2008).

The presence of neutralizing antibodies in the serum of chickens has long been recognized as a major determinant of resistance to infection by avian encephalomyelitis virus (Tannock \& Shafren, 1994). It was demonstrated that maternal antibodies in the chick yolk sac are fully absorbed between the second and third week post-hatch (Szabó, 2012). Therefore, the detection of antibodies against AEV in a flock of chickens with 21 days of age or older indicates field infection.

The best way to prevent and to control the disease is vaccinating breeder flocks during their grow-out period, preventing the infection of breeders during the egg production period, and thereby, virus transmission to the progeny. Moreover, breeder vaccination provides good immunization of progeny, ensuring protection against virus infection during the first weeks of life, when they are most susceptible to the virus (Back, 2010; Calnek, 2008; Martins \& Silva, 2009; Roy et al, 2009).
In Brazil, the avian encephalomyelitis virus appeared to be very well controlled by breeder vaccination for many years (Back, 2010). However, the recent increase in the number of cases of avian encephalomyelitis has been a cause of concern in the poultry industry. Therefore, the aim of this study was to evaluate the occurrence of that disease in southern Brazil in the last five years.

\section{MATERIAL AND METHODS}

This study evaluated the results of histopathological diagnosis and serology tests performed by MercoLab Laboratórios Ltda., Cascavel, state of Paraná, Brazil. Data from broilers with between one to 35 days of age were studied. Samples derived from poultry farms located in southern Brazil and with suspected evidence of avian encephalomyelitis. Typically, the clinical history reported neurological symptoms such as paralysis, incoordination, neck tremors, and mortality rates ranging from moderate to high (1 to 10\%). Data for this study were obtained from January 2009 to December 2013. During that period, 103 broiler flocks suspected of having the disease were evaluated.

The received samples (organs fixed in 10\% formalin and serum) were collected by the veterinarian on the farm and submitted to the laboratory. Live birds with clinically suspected signs of the disease were occasionally taken to the laboratory for sample collection. For histopathological analyses, tissue fragments were processed according to routine techniques, including paraffin embedding and staining with hematoxylin-eosin (HE). Briefly, tissues were dehydrated in graded alcohol series $(70 \%$ alcohol to absolute alcohol), cleared in xylene, and embedded in paraffin. Subsequently, 2 - to $4-\mu \mathrm{m}$ thick sections of the pancreas, brain, gizzard, proventriculus, and heart were cut using an automatic microtome (Leica RM 2125 NT). After deparaffinization in an oven at $60^{\circ} \mathrm{C}$ overnight, tissue samples were hydrated in decreasing alcohol series and stained with hematoxylin and eosin (HE).

Encephalon, pancreas, proventriculus, gizzard and heart samples were examined under light microscopy by a veterinary pathologist for the microscopic observation of pathognomonic histopathological lesions of $A E$. Histopathological analysis results were only included if the observed microscopic lesions were compatible with avian encephalomyelitis and associated with clinical symptoms in the field. The evolution of the group of cases was evaluated per month and per year. Data 
were analyzed with the aid of likesoftware programs (Excel, Microsoft) and graphs and charts were created to illustrate the results.

In addition to the histopathological evaluation, the sera of broilers older than 21 days were tested by ELISA (Enzyme Linked Immunosorbent Assay) to determine antibody titers against the avian encephalomyelitis virus. Flocks were considered negative when not presenting seroconversion for the pathogen and positive when seroconversion was detected after 21 days of life. All samples were analyzed under the same conditions using a commercial kit (IDEXX) and according to the manufacturer's recommendations. Only the sera of broilers older than 21 days were analyzed in order to prevent any possible interference of maternal antibodies.

\section{RESULTS AND DISCUSSION}

The results of this study are shown on the tables, figures and graphs below. Avian encephalomyelitis diagnosis was carried out based on the histopathological changes described by Swayne (2008) and on the symptoms observed in the field (Figure 1).

The histopathological sections of the central nervous system showed an accumulation of lymphocytic cells in the perivascular space (perivascular cuffing) in multifocal areas, as well as neuronal necrosis, central chromatolysis and severe gliosis (Figures 2A and B). The muscle layer of the proventriculus, gizzard, and myocardium and the pancreatic interstitium revealed a large number of clusters of lymphocytic inflammatory infiltrate (Figures 3 A, B, C and D). These microscopic findings are considered pathognomonic of avian

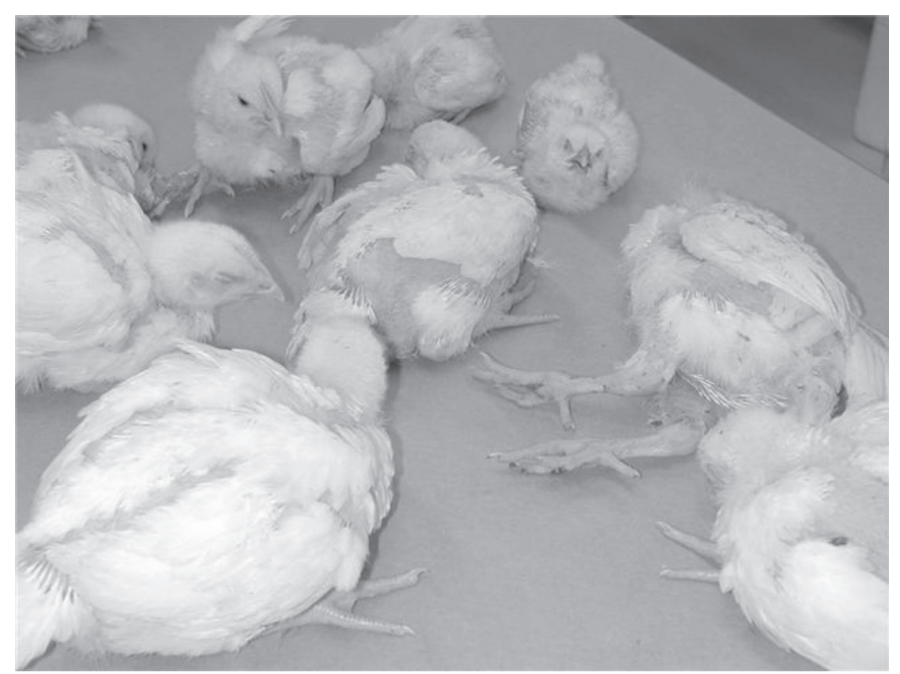

Figure 1 - Two-week-old broiler presenting neurological signs of avian encephalomyelitis virus infection.

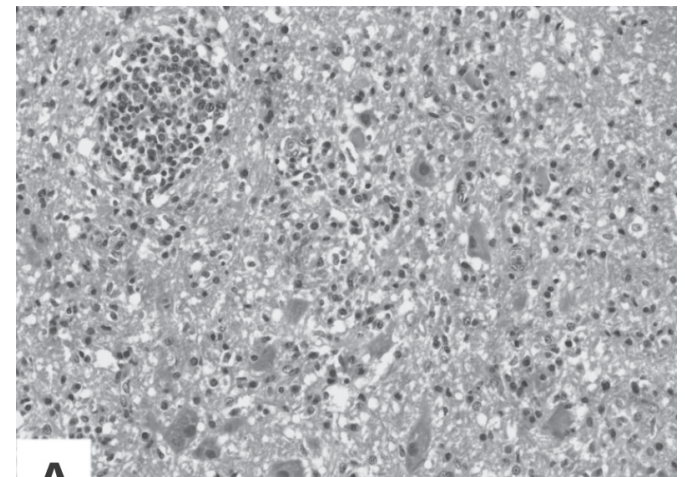

A

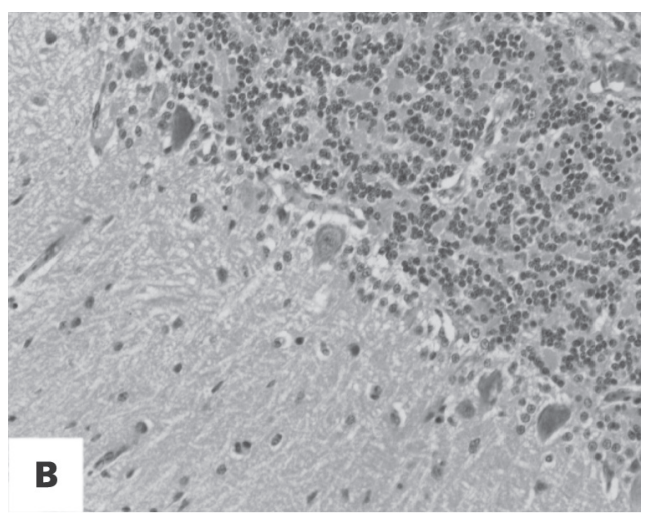

Figure 2 - Central nervous system of a two-week-old broiler with avian encephalomyelitis. A) Perivascular cuffs showing marked multifocal gliosis. B) Degeneration and necrosis of neurons with central chromatolysis.

encephalomyelitis and are consistent with the findings of Martins \& Silva (2009), Roy et al. (2009), Calnek (2008), Swayne (2008), Taylor et al. (1995), Randall (1991), and Butterfield et al. (1969).

The histological changes presented in Figures 2 and 3 are considered pathognomonic for the diagnosis of avian encephalomyelitis, according to Calnek (2008).

In addition to the histopathological findings, high levels of antibodies against the avian encephalomyelitis virus were detected in sera of broilers older than 21 days. Considering that the maternal antibodies transmitted to the progeny do not last longer than two to three weeks after hatching (Szabó, 2012; Kowalczyk et al, 1985; Gharaibeh et al, 2008), it is concluded that the detection of antibodies confirms that the chickens had previous contact with the field virus (Graph 1).

The monitoring data of avian encephalomyelitis cases of 2012, and especially of 2013, caught our attention. As shown in Table 1 and Graph 2, the histopathological results reveal a significant increase in the frequency of the disease from the last quarter of 2012 and peaked in May and August of 2013. In 2009 and 2010, no cases of avian encephalomyelitis were 

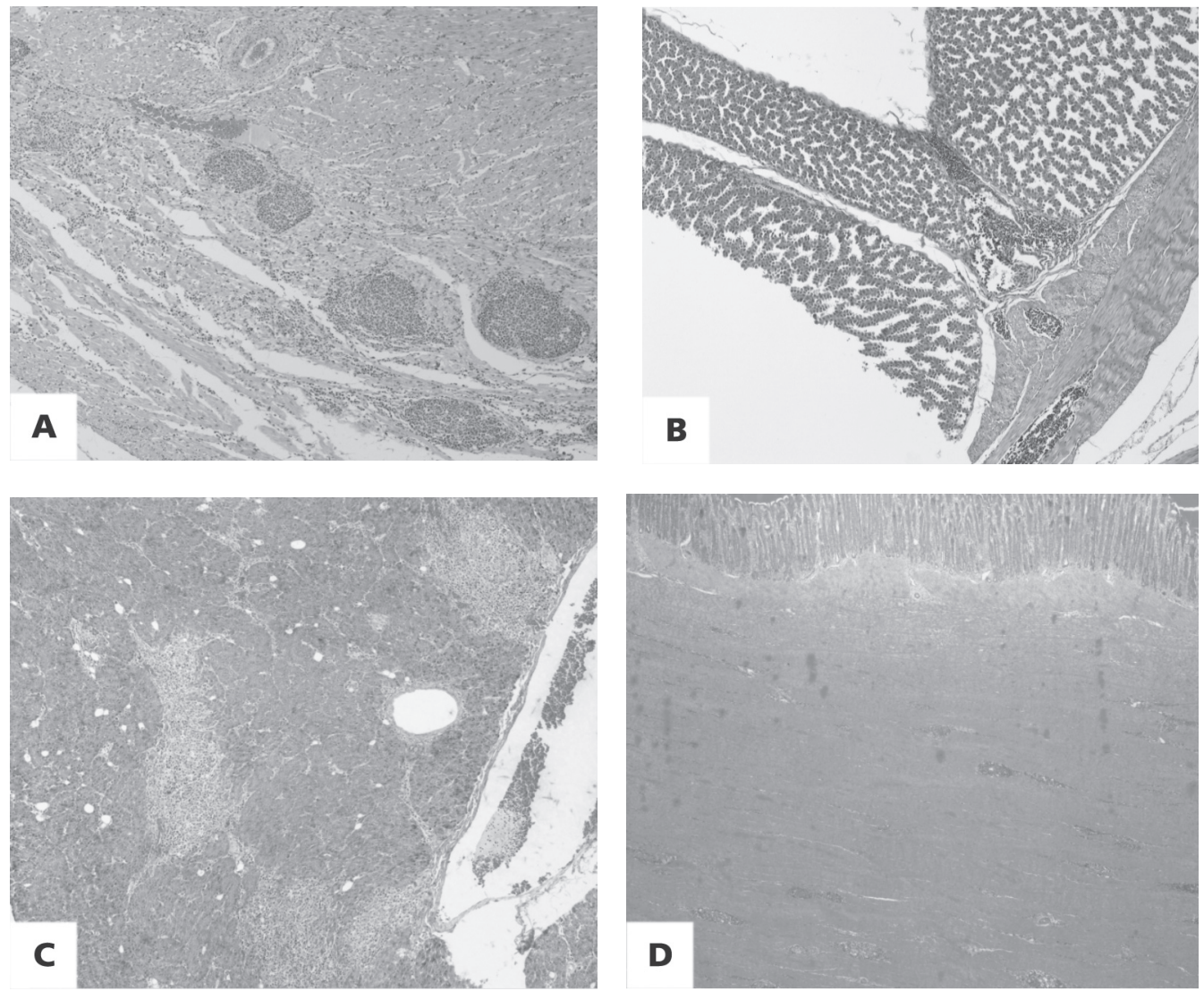

Figure 3 - Two-week-old broiler showing lymphocytic inflammatory infiltrate in: A) Heart, B) Proventriculus, C) Pancreas, D) Gizzard.

detected. These findings support the results described in literature (Calnek, 2008), which demonstrate that, overall, vaccines work very well and prevent the infection, unless breeder immunization mistakes are made (related to the vaccine or vaccination). Immunization errors during the rearing period allow breeder infection during the egg production period, and consequently transmission of the virus to the progeny and manifestation of the disease during the first two weeks of life. Considering the current outbreaks detected in the present study, our hypothesis is that there was a vaccination failure as well as possible low capacity of the virus to induce full immunity.

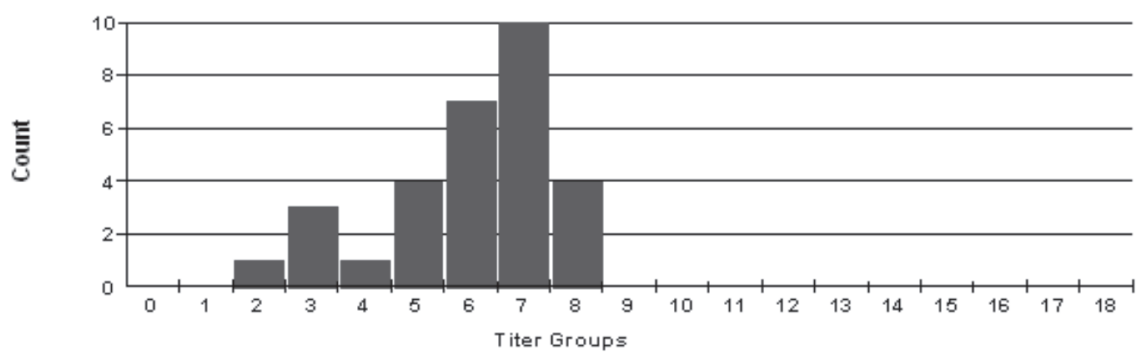

$\begin{array}{lr}\text { Count: } & 30 \\ \text { Mean: } & 5776 \\ \text { GMean: } & 5393 \\ \text { SD: } & 1879 \\ \text { \%CV: } & 32,5 \\ \text { Min: } & 1706 \\ \text { Max: } & 9381 \\ \text { Tech: } & \text { FC } \\ \text { Date: } & 13 / 8 / 13 \\ \text { Dil: } & 1: 500\end{array}$

Graph 1 - Serology results (ELISA) of 3-week-old broilers, showing seroconversion for the avian encephalomyelitis virus. The serum titers are shown in the $x$ axis and the number of serum samples in the $y$ axis. 
Table 1 - Number of cases of avian encephalomyelitis diagnosed by histopathology between January 2009 and December 2013 and the number of poultry companies involved.

\begin{tabular}{l|c|c}
\hline Year/Month & $\begin{array}{c}\text { Cases diagnosed by } \\
\text { histopathology }\end{array}$ & $\begin{array}{c}\text { Companies } \\
\text { involved }\end{array}$ \\
\hline January to December/2009 & 0 & 0 \\
\hline January to December/2010 & 0 & 0 \\
\hline May/2011 & 4 & 4 \\
\hline October/2012 & 8 & 2 \\
\hline November/2012 & 6 & 3 \\
\hline December/2012 & 1 & 1 \\
\hline January/2013 & 5 & 3 \\
\hline February/2013 & 5 & 5 \\
\hline April/2013 & 9 & 5 \\
\hline May/2013 & 15 & 3 \\
\hline July/2013 & 6 & 3 \\
\hline August/2013 & 14 & 5 \\
\hline December/2013 & 4 & 1 \\
\hline
\end{tabular}

Graph 2 shows that there were no cases of avian encephalomyelitis in 2009 and 2010, and that just a few cases were observed in 2011; however, these numbers started to increase in the last quarter of 2012, with 15 cases distributed in four companies. These numbers increased nearly four times in 2013 , totaling 58 cases distributed among 25 poultry companies in southern Brazil. The peak occurred in May and August 2013, with 15 and 14 cases, respectively.

These results show that the problem has spread to several companies in a short time and in a large region. Considering the large number of cases, it appears that the cause was not a single mistake, but a wide range of factors, reaching several states and a large number of poultry companies, may contributed. The possibility of the emergence of new strain of Enterovirus and that the current vaccine strains are no longer protecting the flocks is speculated. However, literature and epidemiological data have not shown any evidences for that support such hypotheses. By monitoring the outbreak, it appears that these cases of avian encephalomyelitis are most likely due to vaccine or vaccination failures. These could be related to vaccine viral seed changes, virus attenuation, vaccine titer changes, vaccine conservation errors, errors in vaccination procedures, and vaccination program changes. It seems that breeders were not adequately immunized during the rearing period and became infected during the egg production period, thereby transmitting the virus to the progeny during a certain time, which resulted in disease in the field. Further studies are required to elucidate possible predisposing factors for these outbreaks. Meanwhile, we suggest the monitoring of breeders after vaccination to ensure their contact with the vaccine virus and that they produce antibodies before the egg production period. In case of weak response, revaccinate the breeders to guarantee good protection and transference of immunity to the progeny.

\section{CONCLUSION}

The clinical, histopathological, and serological evidences obtained in the present study showed a

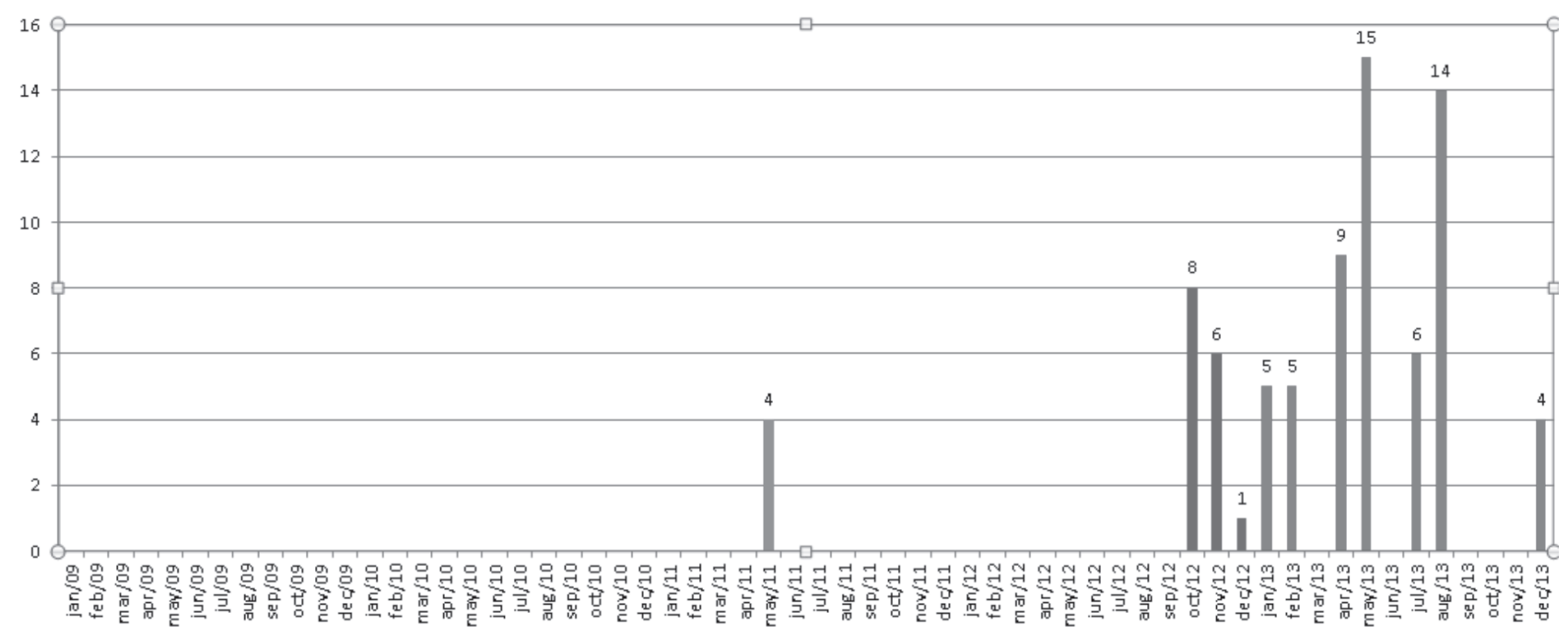

Graph 2 - Graphical distribution of avian encephalomyelitis cases diagnosed by histopathology and serology between January 2009 and December 2013 . The number of cases is shown in the $y$ axis and the period (month/year) in the $x$ axis. 
significant increase of cases of avian encephalomyelitis in broilers from the last quarter of 2012 until the end of 2013. The cause of this increase is not yet clear, but vaccine or vaccination failures are suspected. The monitoring of breeders before the beginning of egg production and the application of two vaccinations, if necessary, are suggested.

\section{REFERENCES}

Asasi K, Farzinpour A, Tafti AK. Clinico-Pathological Studies on Avian Encephalomyelitis in Shiraz, Iran. Turkish Journal of Veterinary and Animal Sciences 2008;3(3):229 - 231.

Back A. Encefalomielite aviária. In: Back A. Manual de doenças de aves. $2^{\text {a }}$ ed. Cafelândia : Editora Integração; 2010. p. 70-2.

Butterfield, W.K., Helmboldt, C.F., Luginbuhl, R.E. Studies on avian encephalomyelitis. IV. Early incidence and longevity of histopathological lesions in chickens. Avian Diseases 1969;13:53-57

Calnek BW. Avian encephalomyelitis. In: Saif YM. Diseases of poultry. $12^{\text {th }}$ ed, lowa: Blackwell; 2008. p. $430-41$.

Calnek BW. Control of avian encephalomyelitis: a historical account. Avian Diseases 1998:42:632 -647.

Gharaibeh S, Mahmoud K. Decay of maternal antibodies in broiler chickens. Poultry Science 2013; 92:2333 - 2336.
Gharaibeh S, Mahmoud K, Al-Natour M. Field evaluation of maternal antibody transfer to a group of pathogens in meat-type chickens. Poultry Science 2008;87:1550 -55.

Kowalczyk K, Daiss J, Halpern J, Roth TF. Quantification of maternal-fetal IgG transport in the chicken. Immunology 1985;54:755- 62.

Martins PC, Silva PL. Encefalomielite aviária. In: Berchieri Jr A, Silva EN, Di Fábio J, Sesti L, Zuanase MAF. Doença das aves. $2^{\text {th }}$ ed Campinas: Facta; 2009. p.763 - 74

Randall CJ. Diseases and disorders of the domestic fowl and turkey. $2^{\text {th }}$ ed Barcelona: Mosby-Wolfe; 1991. p.66-68.

Roy P, Hemalatha S, Vairamuthu S, Purushothaman V, Chandramohan A, Karunamurthy G, Koteeswaran, A, Muralimanohar, B. An outbreak of avian encephalomyelitis in Tamil Nadu State of India. West Indian Veterinary Journal 2009;9 2):8 -10.

Swayne DE. Nervous system. In: Fletcher OJ. Avian histopathology. $3^{\text {rd }}$ ed. Jacksonville: AAAP; 2008. p.58-79.

Szabó C. Transport of IGY from egg-yolk to the chicken embryo. Journal of Microbiology, Biotechnology and Food Sciences 2012;2(3):612 -20.

Tannock GA, Shafren DR. Avian encephalomyelitis: a review. Avian Pathology 1994;23:603 - 620 .

Taylor LW, Lowry DC, Raggi LG. Effects of an outbreak of avian encephalomyelitis (epidemic tremor) in a breeding flock. Poultry Science 1995;34:1036-45.

Villareal L. Encefalomielite aviária. In: Revolledo L, Ferreira AJP. Patologia aviária. Barueri: Manole; 2009. p. 234 - 39. 